[7] Буряковий цукор технології виробництва / M.І. Бахмат, М.I. Ігнатьев, І.А. Вітвіцький. - Кам'янець Подільський: Абетка - НОВА. 2004.-372c;

[8] Системы автоматизации технологических процессов сахарного производства / О.Яковлев, С. Танцюра, А. Войтюк, Ю. Рудаков, С. Латышев, В. Волков, М. Рак, Н. Круглый // Пищевая промышленность. 2000 - №1. - C.44-53.

References

[1] Tehnichni informatsiyni resursi. [Elektronniy resurs] : [Veb-sayt]. - Elektronni dani. - Kiyiv :CAMOZZI. Rezhim dostupu do katalogu.: http://catalog.camozzi.ua - Nazva z ekranu;

[2] Povyshenie urovnja tehnologicheskoj jeffektivnosti truboprovodnoj armatury pozicionnym jelektropnevmoprivodom // Zh-1 «Avtomatizacija tehnologichnih ta biznes-procesiv». - Odessa:ONAHT t.№7(1)/2015.- S.68-74;

[3] A.I.Goshko Armatura truboprovodnaja celevogo naznachenija/ Moskva.- Mashinostroenie.- 2003.- 280s;

[4] Koncepcii povyshenija jeffektivnosti ASU TP pri proizvodstve sahara v Ukraine / S.A. Ljashenko, A.S. Ljashenko, I.S. Beljaeva // Suchasni naprjamki tehnologiï ta mehanizaciï procesiv pererobnih $\mathrm{i}$ harchovih virobnictv. Visnik HNTUSG. - Harkiv: HNTUSG, 2008. - Vip. 74. - S. 54-63;

[5] Strategija avtomatizacii proizvodstva sahara / Belousov V.Ju., Litvinov A.F.. Potapov O.A., Gorchinskij Ju.N. // Sahar. -2002.-№1.- S. 28-33;

[6] Sapronov A.R. Tehnologija saharnogo proizvodstva / Sapronov A.R. -M.: Agropromizdat, 1986. - 436s.

[7] Burjakovij cukor tehnologiï virobnictva / M.I. Bahmat, M.I. Ignat'ev, I.A. Vitvic'kij. - Kam'janec' - Podil's'kij: Abetka - NOVA. 2004.-372s;

[8] Sistemy avtomatizacii tehnologicheskih processov saharnogo proizvodstva / O.Jakovlev, S. Tancjura, A. Vojtjuk, Ju. Rudakov, S. Latyshev, V. Volkov, M. Rak, N. Kruglyj // Pishhevaja promyshlennost'. 2000 - №1. - S.44-53.

\title{
СИСТЕМА АВТОМАТИЧЕСКОГО РЕГУЛИРОВАНИЯ РАСХОДА СЫПУЧЕГО МАТЕРИАЛА
}

The system automatically controlling the flow of bulk material

Павлов А.И. ${ }^{1}$

${ }^{1}$ Одесская национальная академия пищевых технологий, г. Одесса

Copyright (C 2014 by author and the journal "Automation technological and business - processes". This work is licensed under the Creative Commons Attribution International License (CC BY). http://creativecommons.org/licenses/by/4.0/

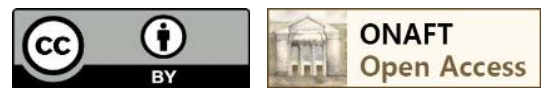

DOI: $10.15673 /$

\begin{abstract}
Аннотация
Задача управления расходом сыпучих материалов является весьма актуальной при автоматизации производственных процессов, связанных с необходимость измельчения, смешивания, растворения, сушки, обжига различных компонентов. Использование в системах автоматического регулирования разнообразных питателей приводит к большим финансовым затратам как на стадии их создания, так и при эксплуатации. Альтернативным решением задачи регулирования расхода сыпучих материалов является использование в качестве регулирующего органа подбункерных задвижек. При этом не требуется измерять величину расхода сыпучего материала. В качестве регулируемой координаты используется косвенный параметр величина открытия задвижки. Необходимая величина открытия задвижки для обеспечения заданного
\end{abstract}


расхода сыпучего материала определяется с использованием известной функциональной связи между ними. Для реализации системы автоматического регулирования требуется наличие в исполнительном механизме датчика положения шибера задвижки.

\begin{abstract}
The task of controlling the flow of bulk materials is very urgent during the automatisation of production processes, associated with the necessity of grinding, mixing, dissolving, drying, firing of various components. The use of various feeders in automatic control systems leads to great financial costs in the project stage and during operation. The alternative solution for controlling the consumption of bulk materials, is the usage of silo bin gate as control mechanism. Thus there is no need to measure the flow of bulk material. As a regulated coordinates was used indirect parameter - the value of the bin gate opening. The required value of the bin gate opening for providing current flow of bulk material is calculated using the known functional connection between them. To implement the automatic control system it is necessary to provide availability in actuating mechanism bin gate position sensor.
\end{abstract}

Ключевые слова

Сыпучие материалы, регулирование расхода, подбункерная задвижка.

Постановка проблемы

Задача управления расходом сыпучего материала является весьма типичной для автоматизации производственных процессов измельчения, смешивания, растворения, дозирования и др. Известно множество разработок систем автоматического регулирования (САР) разнообразных сыпучих материалов. В их основе лежит прямое измерение расхода сыпучего материала с использованием тех или иных физических явлений. К числу современных средств измерения расхода различных твердых веществ и их смесей с гранулометрическим составом от 1 нм до 0,1 м относятся, например, SolidFlow, MaxFlow, DensFlow, ClampFlow. Величина погрешности измерения указанных расходомеров достигает $3 . .5 \%$ при стоимости от 150000 до 300000 гривен за штуку. Это вынуждает искать другой способ получения информации о величине расхода сыпучего материала, не требующий использования расходомеров. Но возможно ли это? Да, в некоторых случаях можно построить САР расхода сыпучего материала, используя косвенный параметр, находящийся в прямой корреляции с величиной расхода, тем более, что часто не требуется высокая точность его измерения.

В качестве исполнительных устройств (ИУ) в системах управления расходом сыпучих материалов широко применяются разнообразные питатели (барабанные, ленточные, вибрационные, лопастные, шнековые и др.). В числе их недостатков следует также отметить: а) большие первоначальные денежные затраты на создание САР изза необходимости наличия в канале управления преобразователя частоты (ПЧ) напряжения электродвигателя; б) они постоянно используют энергию электрического тока при своей работе, то есть для них свойственны значительные денежные расходы и при эксплуатации; в) необходимость расходомера и ПЧ обусловливают снижение надежности САР.

Альтернативой питателям являются подбункерные (подсилосные) задвижки, к числу достоинств которых относятся: простота конструкции, высокая надежность и долговечность, небольшая стоимость создания САР (в варианте отсутствия в ней расходомера), очень маленькие, буквально мизерные, эксплуатационные расходы. Именно использование в составе ИУ в качестве регулирующего органа (РО) подбункерных (реечных либо винтовых) задвижек и позволяет при построении САР расхода сыпучего материала использовать косвенный параметр, коррелированный с текущей величиной расхода.

Основная часть. В качестве косвенного параметра, находящегося в прямой корреляции с текущей величиной расхода сыпучего материала, можно использовать один из геометрических параметров задвижки - величину линейного перемещения затвора регулирующего органа - шибера. Обозначим координату положения шибера через «а» (м). Подбункерные задвижки имеют квадратную форму отверстия со стороной b, через которое и движется самотеком сыпучий материал, если а > 0. Сторона квадрата, то есть ширина отверстия широко используемых задвижек, $0,2 \leq \mathrm{b} \leq 0,5$, м; $\mathrm{b}=$ const. Параметр «а» однозначно определяет степень открытия задвижки, причем $0 \leq \mathrm{a} \leq \mathrm{b}$.

Экспериментально установлена зависимость величины расхода Q сыпучего материала от величины «а» открытия задвижки при различных величинах b и различных видах сыпучих зернопродуктов [1]. Так, например, в таблице приведены результаты измерений величины объемного расхода пшеницы с плотностью $\rho=750$ кг/м ${ }^{3}$ и $\mathrm{b}=$ $0,3 \mathrm{M}$.

Наиболее близкой к экспериментальной расходной характеристике такого РО является зависимость: 


$$
Q=45 \frac{(a b)^{2}}{a+b} \rho, \mathrm{T} / \mathrm{Y}
$$

Результаты вычисления величины расхода $\mathrm{Q}=\mathrm{f}(\mathrm{a})$ по формуле (1) приведены в таблице:

\begin{tabular}{|c|c|c|}
\hline $\begin{array}{c}\text { Величина открытия шибера «а», } \\
\text { M }\end{array}$ & $\begin{array}{c}\text { Величина расхода по данным } \\
\text { экспериментов, т/ч }\end{array}$ & $\begin{array}{c}\text { Величина расхода по формуле (1), } \\
\text { т/ч }\end{array}$ \\
\hline 0,04 & 14,976 & 14,290 \\
\hline 0,05 & 21,528 & 21,690 \\
\hline 0,06 & 31,320 & 30,375 \\
\hline 0,07 & 39,672 & 40,223 \\
\hline 0,08 & 51,192 & 51,155 \\
\hline 0,09 & 62,928 & 63,085 \\
\hline 0,10 & 73,080 & 75,937 \\
\hline
\end{tabular}

Практически же необходимо решать обратную задачу: задана величина объемного расхода и требуется открыть задвижку на соответствующую расходу величину «а».

После выполнения необходимых преобразований из формулы (1) для задвижки, например, $\mathrm{c} b=0,3$ получим:

$$
\mathrm{a}=\frac{\mathrm{Q}+\sqrt{\mathrm{Q}(\mathrm{Q}+4,86 \rho)}}{8,1 \rho}, \mathrm{M}
$$

Аналогичным образом можно получить соответствующие выражения $\mathrm{a}=\mathrm{f}(\mathrm{Q})$ и для других величин $\mathrm{b}$.

В работе [1] представлены результаты экспериментов только для некоторых зернопродуктов и только для двух величин b: 0,3 м и 0,48 м. И хотя геометрия отверстия, через которое движется сыпучий материал, не зависит от величины b (оно всегда представляет прямоугольник площадью $\mathrm{ab}$ ), априори делать вывод о том, что величина расхода зависит только от площади отверстия и не зависит от абсолютной величины b, не будем. Кроме того, следует учитывать, что может происходить смена сыпучего продукта, находящегося в бункере. Поэтому использование расходомеров, например, типа SolidFlow (для продуктопроводов с диаметром до 0,15 м) или MaxFlow (при расходе Q > 20 т/ч) необходимо, но только на период времени выполнения процедур калибровки и экспериментального определения зависимости $\mathrm{a}=\mathrm{f}(\mathrm{Q})$ для каждого вида сыпучего материала.

Для реализации предлагаемого способа построения САР расхода сыпучего материала необходима информация о положении шибера РО. В прошлом в качестве электропривода задвижек широко применялись специализированные исполнительные механизмы РИМЗ, оснащенные реостатными датчиками положения затвора регулирующего органа. В настоящее время наиболее целесообразно задвижки укомплектовывать

электродвигательными исполнительными механизмами (актуаторами), например, серии МЭП (МЭП-2500 МЭП-6300 МЭП-10000 МЭП-25000 и др.). Они выпускаются как в обычном, так и во взрывозащищенном исполнении.

На рис. 1 представлена имитационная модель САР расхода сыпучего материала, реализованная с использованием пакетов программных модулей Simulink в среде MATLAB.

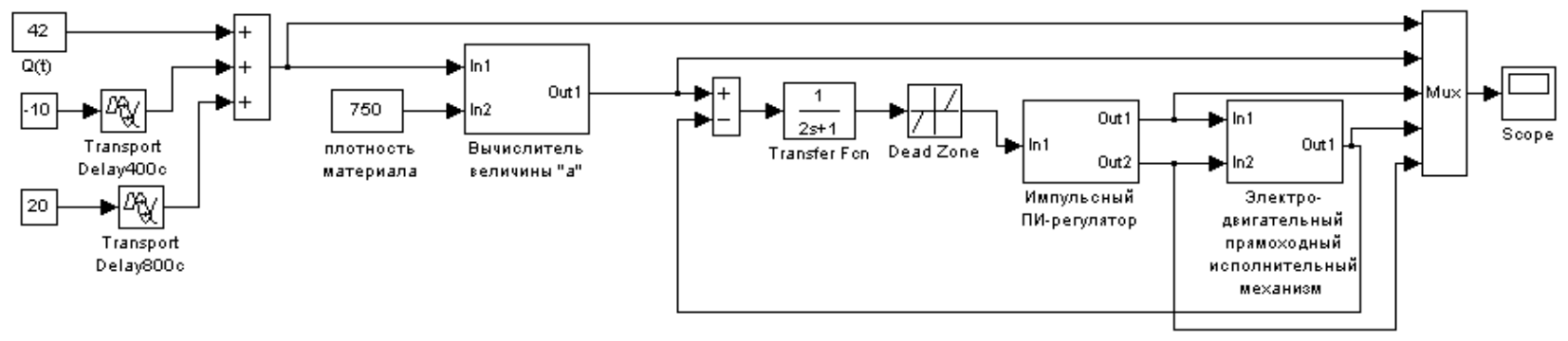

Рис. 1 - Структурная схема имитационной модели САР расхода сыпучего материала

На рис. 2 представлена подсистема, обеспечивающая вычисление величины «а» по заданным значениям расхода $\mathrm{Q}_{3}(\mathrm{t})$ и плотности $\rho$ сыпучего материала в соответствии с формулой (2). 
АВТОМАТИЧНІ ТА АВТОМАТИЗОВАНІ СИСТЕМИ УПРАВЛІННЯ ТЕХНОЛОГІЧНИМИ ПРОЦЕСАМИ

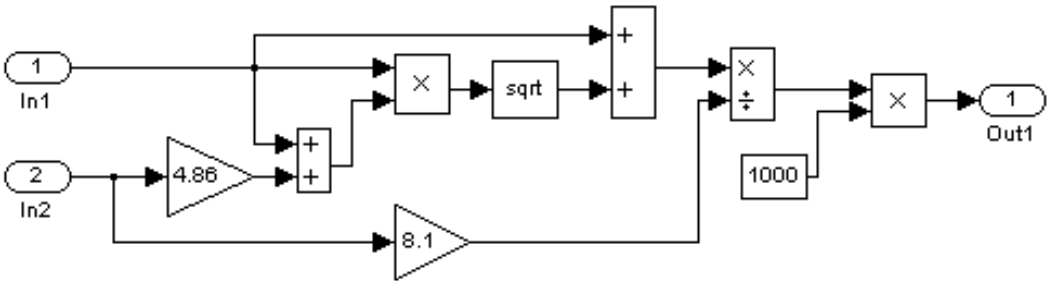

Рис. 2 - Структурная схема вычислителя необходимой величины открытия задвижки $(\mathrm{b}=0,3$ м)

Имитационная модель исполнительного устройства, оснащенного электродвигательным прямоходным механизмом МЭП, представлена на рис. 3.

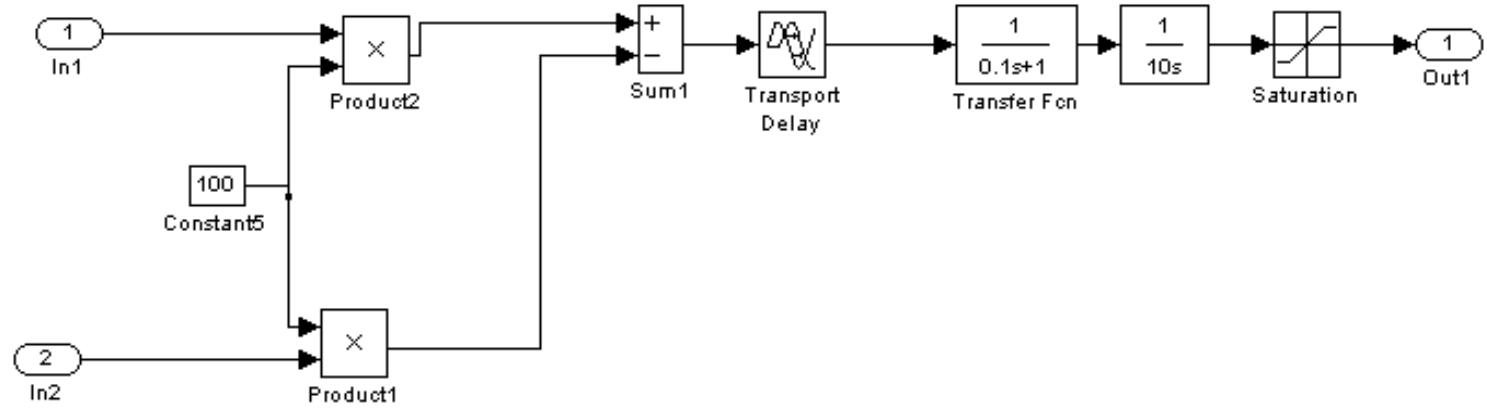

Рис. 3 - Имитационная модель электродвигательного исполнительного механизма постоянной скорости

На рис. 4 приведены графические результаты моделирования (заданная и фактическая величины открытия «а» задвижки выражены в мм).

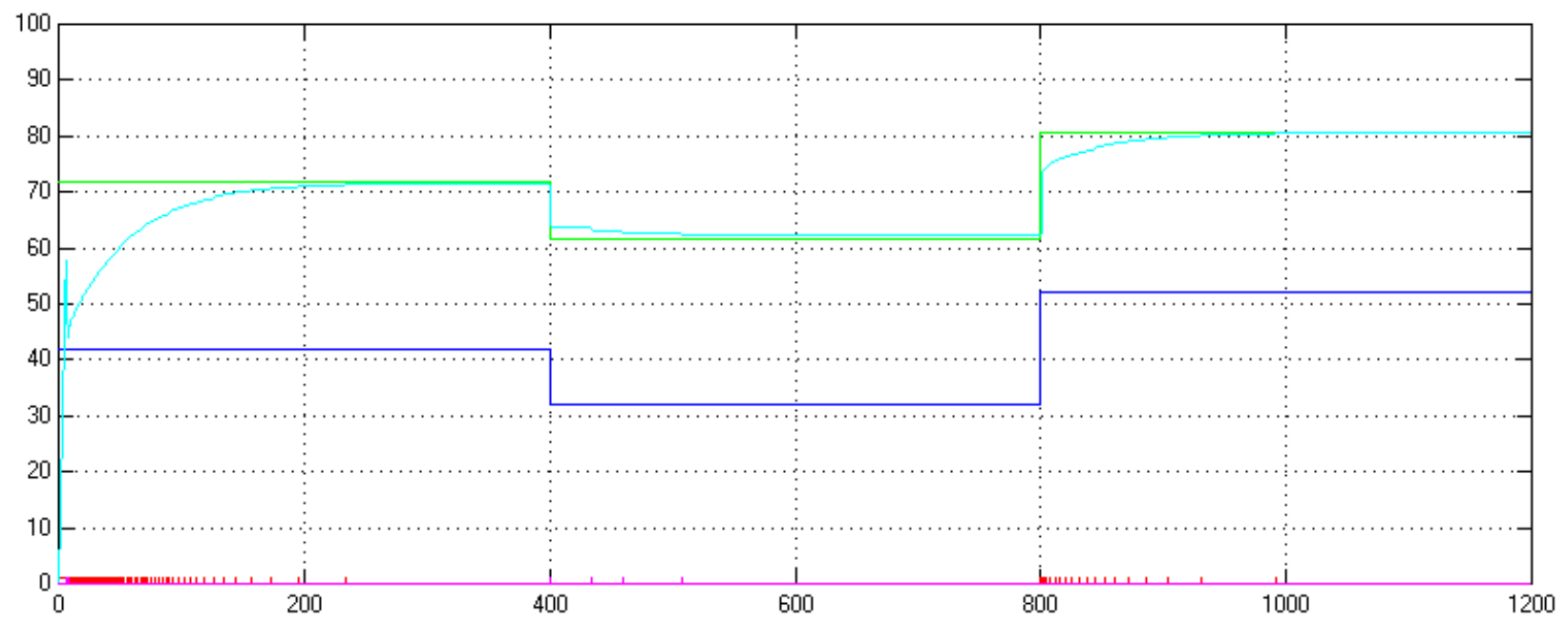

Рис. 4 - Результаты имитационного моделирования САР расхода сыпучего материала

\section{Выводы}

1. Подбункерные задвижки, по сравнению со всеми другими регулирующими средствами воздействия на расход сыпучего материала, имеют самые низкие финансовые и энергетические затраты на реализацию функции управления;

2. Между положением затвора регулирующего органа задвижки и величиной расхода сыпучего материала имеется функциональная связь, знание которой позволяет управлять потоком сыпучего материала без необходимости прямого измерения его расхода;

3. Система автоматического регулирования легко реализуется как в технической, так и в программируемой ее части, что обусловливает низкую стоимость ее создания. 


\section{Литература}

[1] Банит Е. А. Исследование процессов истечения сыпучих материалов из отверстий сосудов : дис. канд. техн. наук / Банит Евгений Александрович. - Одесса, 1959. - 176 с;

[2] Птушкин А. Т. Автоматизация производственных процессов в отраслях хранения и переработки зерна [Текст] / А. Т. Птушкин, О. А. Новицкий // М. : Агропромиздат, 1985. - 318 с;

[3] Новицкий О. А. Автоматизация производственных процессов на элеваторах и зерноперерабатывающих предприятиях [Текст] / О. А. Новицкий, В. С. Сергунов // М. : Колос, 1981. - 319 с.

\section{References}

[1] Banit Ye. A. Issledovaniye protsessov istecheniya sypuchih materialov iz otverstiy sosudov : dis. kand. tehn. nauk / Banit Yevgeniy Aleksandrovich. - Odessa, 1959. - 176 str;

[2] Ptushkin A. T. Avtomatizatsiya proizvodstvennyh protsessov v otraslyah khraneniya i pererabotki zerna [Tekst] / A. T. Ptushkin, O.A. Novitskiy // M.: Agropromizdat, 1985. - 318 str;

[3] Novitskiy O. A. Avtomatizatsiya proizvodstvennyh protsessov na elevatorah i zernopererabatyvayuschih predpriyatiyah [Tekst] / O. A. Novitskiy, V. S. Sergunov // M. : Kolos, 1981. - 319 str.

\section{Е НОВОСТИ АВТОМАТИЗАЦИИ}

\section{Connecting Industrie 4.0.}

Earlier this year at the Hannover Fair event in Hannover, Germany, Harting, a supplier of cables, connectors and switches for industrial automation applications, made it clear that Industrie 4.0 was going to play an increasingly important role in the company's new product development and overall direction. At the SPS/IPC/Drives annual event in Nuremberg last month, further evidence of Harting's movement in this direction were made clear as the company spotlighted its MICA modular platform, Infrastructure Box, and wireless sensor embedded transponder base.

At the core of Harting's Industrie 4.0 focus is MICA, a modular platform of open hardware and software that can be adapted to various industrial application areas. The platform consists of a compact computer which conforms to EN 50155, making it suitable for industrial and rail applications. Using Linux software, the MICA platform enables the virtualization of applications on field devices, allowing for applications to be run in development sandboxes that contain the required libraries and drivers for the application. As a result, package dependencies and incompatibilities can be assessed and avoided before deployment.

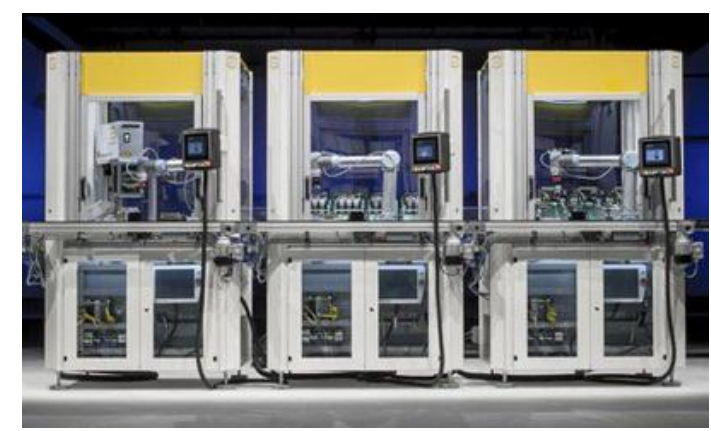

